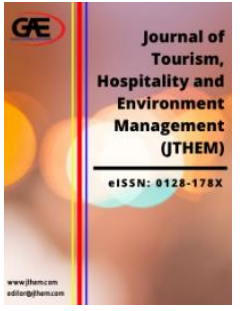

\author{
JOURNAL OF TOURISM, \\ HOSPITALITY AND \\ ENVIRONMENT MANAGEMENT \\ (JTHEM) \\ www.jthem.com
}

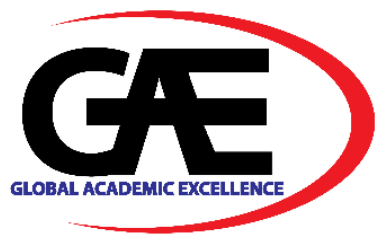

\title{
ENERGY KNOWLEDGE IN INFLUENCING HOUSEHOLD'S ENERGY CONSERVATION BEHAVIOUR
}

\author{
Nur Azzlin Mangsor ${ }^{1}$, Low Sheau-Ting ${ }^{2 *}$
}

1 Department of Real Estate, Faculty of Built Environment and Surveying, Universiti Teknologi Malaysia, 81310

Johor Bahru, Johor, Malaysia

Email: nurazzlinangsor@gmail.com

2 Department of Real Estate, Faculty of Built Environment and Surveying, Universiti Teknologi Malaysia, 81310

Johor Bahru, Johor, Malaysia

Email: sheauting@utm.my

* Corresponding Author

\section{Article Info:}

Article history:

Received date: 01.10 .2021

Revised date: 01.11.2021

Accepted date: 15.11.2021

Published date: 01.12.2021

\section{To cite this document:}

Mangsor, N. A., \& Sheau-Ting, L. (2021). Energy Knowledge In Influencing Household's Energy Conservation Behaviour. Journal of Tourism Hospitality and Environment Management, 6 (26), 215-222.

DOI: $10.35631 /$ JTHEM.626019.

This work is licensed under $\underline{\text { CC BY } 4.0}$ (c)

\section{Abstract:}

Malaysia needs to ensure stable energy consumption to improve environmental quality and energy security. The increasing trend of the country's population growth and economic development are parallel with the country's overall energy demand. The building sector, commercial and residential sector has contributed to more than $12 \%$ of the country's final energy consumption in the year 2018. The energy demand from the household sector is on an increasing trend. The residential sector is responsible for the increasing trend of energy consumption with the improvement of lifestyle and living standards. Variation in residents' behaviour can cause significant differences in energy consumption due to dwellings, household size, income, and building energy consumption. Past studies have shown the identification of the relevant psychological factors that formulating energy conservation behaviour contributed to household energy consumption reduction. By focusing on the psychological dimension, this study explores the role of energy knowledge in influencing energy conservation behaviour among households in Malaysia. Energy knowledge is about the household's understanding in the context of energy-saving and consumption. Despite massive information and awareness of climate change about the contribution of climate change from household energy consumption, many households still do not practice energy conservation actively. By conducting a systematic literature review, this study found that energy knowledge plays an essential role in influencing household energy conservation behaviour. The findings of this study could help the institutions and relevant authorities to gain a better understanding of the role 


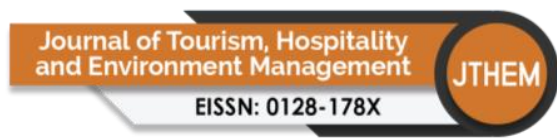

Volume 6 Issue 26 (December 2021) PP. 215-222

DOI 10/35631/JTHEM.626019

of energy knowledge as one of the psychological factors in household energy conservation behaviour.

Keywords:

Energy Knowledge, Household, Energy Conservation Behaviour

\section{Introduction}

Energy consumption appears to contribute to the most carbon dioxide $\left(\mathrm{CO}_{2}\right)$ emissions and ultimately lead to global climate change (Zhang and Zhang, 2018a, 2018b). Energy is one of the most important inputs for urbanization, development, and modernization. Rapid urbanization and population growth make many fast-developing countries to be dependent more on energy-intensive. Growth of energy consumption level that parallels with a range of negative environmental impacts, and human health becoming a serious challenge that impedes the sustainable development of the natural and human systems (Song et al., 2019) . Among the different sectors, the residential and commercial sector is one of the major energy consumption contributors that consumed about $12.0 \%$ of Malaysia's total energy in the year 2018 (Energy Commission, 2018). The household is one of the primary and fastest-growing sources of $\mathrm{CO}_{2}$ emissions (Kusumadewi and Limmeechokchai, 2017). The residential sector creates $\mathrm{CO}_{2}$ emissions that can be categorised into direct and indirect emissions. Indirect or embedded emissions from indirect energy consumption in different phases of the lifecycle of products and services such as production, transportation, and marketing (Jakučionytė-Skodienè et al.,2020). For example of the manufacture of a TV made in China, and along with supply chains arising domestically and abroad account for the majority of the carbon footprints of the Western households (Druckman and Jackson, 2016). Meanwhile, direct emissions from the energy consumption at home, the activities in the daily life of residents, such as gas for space and water heating, and electricity for lighting and electrical home appliances and gadgets and fuels (petrol and diesel) for personal transportation (Druckman and Jackson, 2016; JakučionytėSkodienè et al., 2020)

As the population increases, electricity consumption increases in Malaysia significantly. Energy consumption in the residential sector has contributed to the country's total electricity demand. The residential sector consumed $20.5 \%$ of total electricity consumption (Energy Commission, 2018). Most houses were equipped with a wide range of electrical appliances. The households might not aware of the strategies to consume energy efficiently in their daily lives. In recent years, energy conservation behaviour among households has received numerous attention from the community (Boomsma et al., 2019;Song et al., 2019;Thøgersen, 2018; Trotta, 2018). As suggested in previous studies, significant energy reduction can be achieved by promoting energy conservation behaviour among the household. The psychological factors that drive household energy conservation behaviour are becoming more complex across the contexts (Boomsma et al., 2019; Thøgersen, 2018). Awareness to reduce energy consumption at home has been well promoted to households through campaigns and programs, however, energy consumption for residential buildings remains on an increasing trend. Various psychological factors have been identified in the previous research that contributing to individual behaviour, including attitude, social norm, past experience, perceived behaviour control and other psychological factors. For instance, biospheric and altruistic values, environmental concern, and green lifestyle orientation have influenced green 


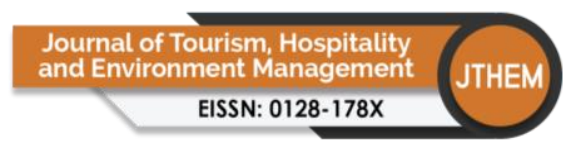

Volume 6 Issue 26 (December 2021) PP. 215-222

DOI 10/35631/JTHEM.626019

technology purchasing intention in both US and Canadian consumers (Berman et al.,2021). A study, Zhang et al. (2019), suggested the personal norm is found to be the major factor influencing the intentions of Chinese residents towards waste sorting.

In the context of household energy conservation, one of the psychological factors influencing household energy conservation behaviour is energy knowledge. Imbulana and Managi (2021) have found that energy knowledge of energy sustainability in 37 countries based on gender with the concepts of holistic associations and cause-effect logic. In the study, most countries reported males having more energy knowledge about energy sustainability with cause-effect logic than females with holistic associations that were beneficial to decision-making processes about energy sustainability and energy conservation practices. In another study, Broek (2019) reviewed on literature of household energy knowledge regarding energy literacy that focus on the understanding of domestic electricity and gas consumption, by providing a framework for categorisation of the different conceptual and methodological approaches. Existing literature presented that four types of household energy knowledge distinguished such as device energy knowledge, action energy knowledge, financial energy knowledge, and multifaceted energy knowledge concerning energy consumption often stimulate energy conservation behaviour.

By understanding how and why to conserve energy, the individuals will tend to be more active towards the energy conservation behaviour. Therefore, this study aims to highlight the significant role of energy knowledge in contributing to energy conservation behaviour.

\section{Energy Knowledge In Influencing Household Energy Conservation Behaviour}

Energy knowledge may drive energy conservation behaviour among households to reduce energy consumption. Energy knowledge has been acknowledged as a psychological factor that has a significant impact on household energy consumption behaviour. A large number of past studies analyzing the energy knowledge impact on energy conservation behaviour have stated that energy represented a catalytic factor in driving energy conservation behaviour impede substantial energy consumption behaviours among households (Anastasya et al., 2021;Kowalska-pyzalska and Byrka, 2019; Stojanovski et al.,2020;Trotta, 2020;Ucal, 2017).

Energy knowledge is defined as the understanding that drives the sustainable consumption of energy by households. According to Kowalska-pyzalska and Byrka (2019), energy knowledge increases the commitment to conserve energy associated with awareness of energy consumption among the households in Poland. In a study conducted by Gołębiowska (2020), the households have demonstrated that their energy literacy contributes to influencing household energy consumption behaviours. Knowledge of renewable energy has been found to affect the willingness of ordinary households to pay in applying renewable energy as an energy source for household electricity needs related to human behaviour or actions in Kepulauan Seribu Regency (Anastasya et al., 2021). A study conducted by Ucal (2017) in analyzing energy consumption behaviours among women in Turkish has indicated that knowledge of energy-efficient electrical home appliances and climate change with energy conservation have significantly influenced their energy conservation behaviour and purchase decision of electrical appliances. Consistently, another study by Trotta (2020) on Finnish households for electricity consumption has shown that information provision about energy consumption and conservation increased knowledge about electricity bills, prices, and costs. The above studies represent the significant role of energy knowledge in influencing household 


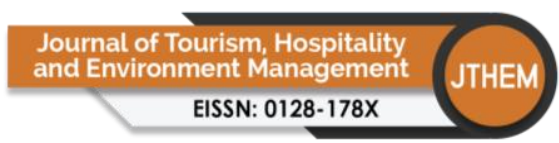

Volume 6 Issue 26 (December 2021) PP. 215-222

DOI 10/35631/JTHEM.626019

energy consumption behaviours towards energy efficiency and the energy conservation behaviours that should be achieved when households consider their energy consumption. A study in Mexico has indicated that improving energy knowledge about energy conservation by helping consumers understand how their electricity-consuming actions and the price schedule they face impact their electricity bill can empower them to make more informed decisions about how much electricity to consume (Stojanovski et al., 2020).

Individuals with good energy knowledge are willing and able to conserve energy, hence perform energy conservation behaviour actively and regularly. This study addresses the link between energy knowledge and energy conservation behaviour. This study presents the essential role of energy knowledge in energy consumption behaviours among households to conserve their energy.

\section{Methodology}

A literature search has been conducted on two databases of a scientific journal: Scopus and Web of Science. The search is limited to articles published from the year 2015 to the year 2021 . Only the work written in English is selected. The keywords used for basis search through the two databases including "energy knowledge", "energy conservation behaviour.", and "household". Also, the basic search extended to identification of all articles that inclusive or synonym of keywords in the same sentence did not limit to title, abstract, and subject field. The search has resulted in a total of fifty-four (54) articles after ensuring that synonyms of "factors", "determinants" and "barriers" are presented in the same field. Lastly, a total of twenty-four studies that considered the significant relationship of the role of energy knowledge influences household energy consumption behaviour were included in the review of present study.

\section{Discussion}

Table 1 shows the 24 related studies on energy knowledge in influencing household energy conservation behaviour. These studies have identified a significant positive relationship between energy knowledge and energy conservation behaviour. The majority of these studies suggested that energy knowledge has changed household energy consumption to conserve energy in fulfilling their daily activities. These studies indicating the relationship between energy knowledge and energy consumption behaviours that drive conserve energy demonstrate households 'understanding of how and why energy consumption to be detrimental and benefited by them.

Table 1: Related Works of Energy Knowledge Influencing Household Energy Consumption Behaviour

\begin{tabular}{|c|c|c|}
\hline No. & Source & Country \\
\hline 1 & Khani et al., 2021 & France \\
\hline 2 & Anastasya et al., 2021 & Indonesia \\
\hline 3 & Jijie et al., 2021 & Romania \\
\hline 4 & Brülisauer et al., 2020 & Singapore \\
\hline 5 & Eriksson and Kjeang, 2020 & Sweden \\
\hline 6 & Stojanovski et al., 2020 & Mexico \\
\hline 7 & Trotta, 2020 & Finland \\
\hline 8 & Li et al., 2020 & China \\
\hline 9 & Diawuo et al., 2020 & Ghana \\
\hline
\end{tabular}




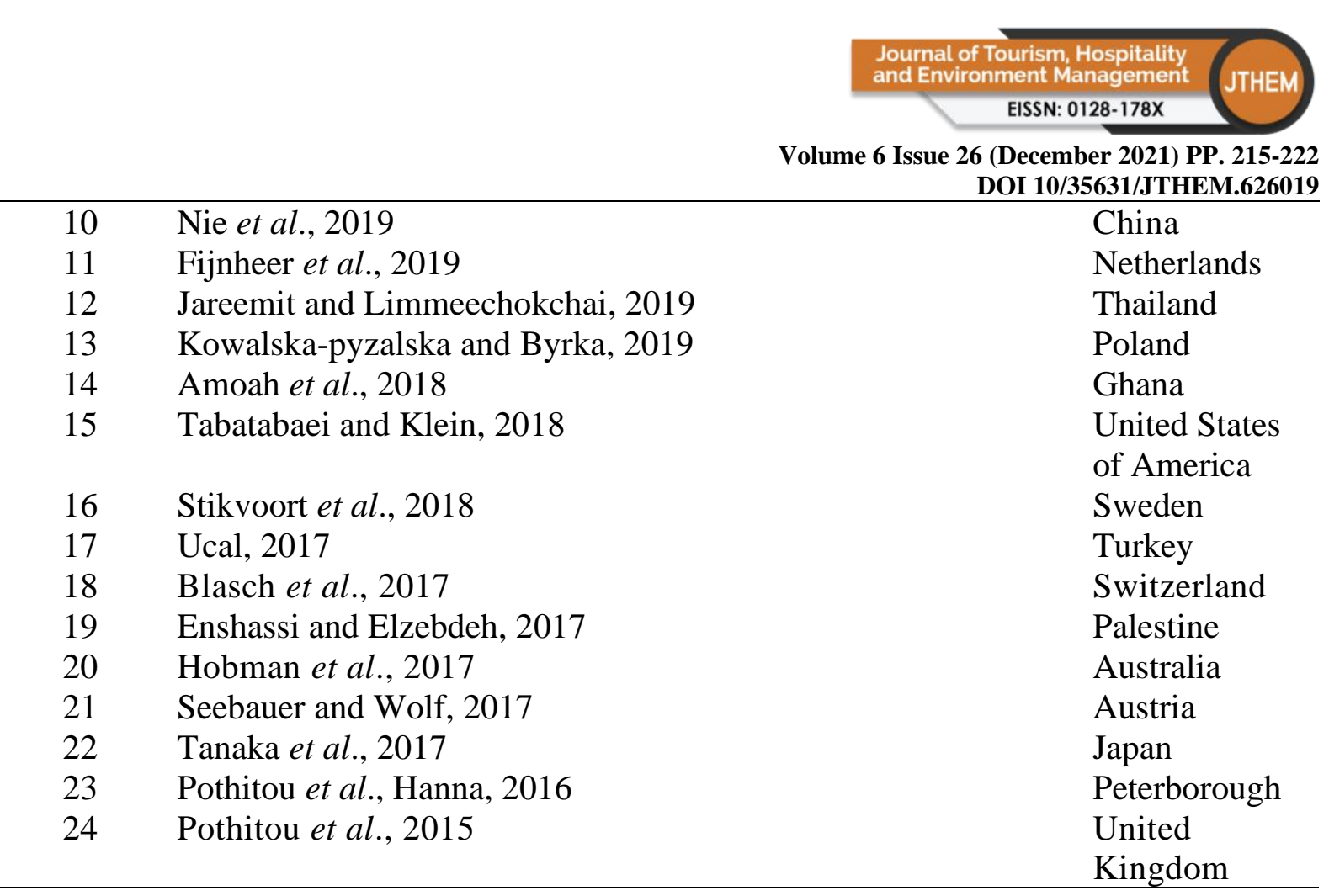

Several studies have linked energy knowledge to influence household energy consumption behaviours significantly and positively (Blasch et al., 2017; Li et al., 2020; Nie et al., 2019; Pothitou et al., 2015).

Blasch et al. (2017) have studied the influence of energy and investment literacy on the level of transient and persistent efficiency in consumption of electricity of households in Switzerland. By analyzing data from the households survey, they found that energy and investment literacy significantly positively exhibiting energy conservation behaviour as households associated with lower electricity consumption, such as energy literacy asserts knowledge relating to the average price of $1 \mathrm{kWh}$ of electricity in Switzerland, the usage cost of different household appliances (running a PC for one hour, running a washing machine cycle with full load), and the electricity consumption of various household appliances. For example, respondents were given two energy services and were asked which of the two consumed more electricity or consumed about the same for boiling one (1) litre of water on the stove rather than boiling one (1) litre of water using an electric kettle.

Nie et al. (2019) have conducted a study of careful use, energy conservation behaviour based on the theory of planned behaviour among the residents in Changchun, China; the results indicated that energy knowledge and information enhanced careful-use behaviours regarding energy conservation behaviours. Likewise, a study of Hefei residents in China, Li et al. (2020) have found that the resident's knowledge of the increasing block tariffs policy for household gas is significantly associated with their acceptance, which has a significant positive impact on residents' gas-conserving intention. A study by Pothitou et al. (2016) have identified that energy knowledge leads to energy conserving activities in households particularly in adopting and purchasing energy-efficient appliances. Similarly, a study found that household knowledge of greenhouse gas emissions, the number of laptops owned and the number of electric showers owned by households associated with households income had a significant positive influence on energy-conservation behaviour (Pothitou et al., 2015). 


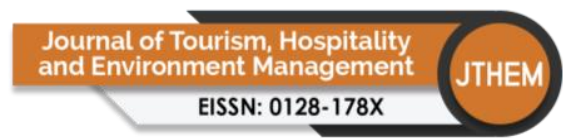

Volume 6 Issue 26 (December 2021) PP. 215-222

DOI 10/35631/JTHEM.626019

\section{Conclusion}

Household energy conservation behaviour contributes to efforts in overcoming sustainability challenges including the increasing trend of energy consumption, climate change and tension to the natural resources. There are essential focuses on the role of energy knowledge to educate and guide households in their energy consumption behaviour to help in achieving energy reduction effectively. Although this study is based on the small number of reviews of the 24 pieces of past works, the findings suggest that emphasis on energy knowledge in influencing household energy conservation behaviour will be able to result in a potential energy reduction as a whole. Unfortunately, this study only includes the review of a single psychological factor that contributes to energy conservation behaviour, further investigation should be conducted to explore other psychological factors that significantly influencing the household energy conservation behaviour, thus contributing to the route of the nation to achieve a sustainable future.

\section{Acknowledgement}

This work was supported by the Ministry of Higher Education Malaysia and Universiti Teknologi Malaysia under the Fundamental Research Grant Scheme [FRGS/1/2018/SS06/UTM/02/1].

\section{References}

Amoah, A., Hughes, G., \& Pomeyie, P. (2018). Environmental consciousness and choice of bulb for lighting in a developing country. Energy, Sustainability and Society, 8(1).

Anastasya, A., Setadi, H., Anggrahita, H., \& Rizqihandari, N. (2021). Society willingness to pay towards application of renewable energy for household electricity needs in Kepulauan Seribu Regency. IOP Conference Series: Earth and Environmental Science, 649(1), 012013.

Blasch, J., Boogen, N., Filippini, M., \& Kumar, N. (2017). Explaining electricity demand and the role of energy and investment literacy on end-use efficiency of Swiss households. Energy Economics, 68, 89-102.

Boomsma, C., Jones, R. V., Pahl, S., \& Fuertes, A. (2019). Do psychological factors relate to energy saving behaviours in inefficient and damp homes? A study among English social housing residents. Energy Research \& Social Science, 47, 146-155.

Van den Broek, K. L. (2019). Household energy literacy: A critical review and a conceptual typology. Energy Research \& Social Science, 57, 101256.

Brülisauer, M., Goette, L., Jiang, Z., Schmitz, J., \& Schubert, R. (2020). Appliance-specific feedback and social comparisons: Evidence from a field experiment on energy conservation. Energy Policy, 145, 111742.

Berman Caggiano, H., Kumar, P., Shwom, R., Cuite, C., \& Axsen, J. (2021). Explaining green technology purchases by US and Canadian households: The role of pro-environmental lifestyles, values, and environmental concern. Energy Efficiency, 14(5).

Diawuo, F. A., Sakah, M., De la Rue du Can, S., Baptista, P. C., \& Silva, C. A. (2020). Assessment of multiple-based demand response actions for peak residential electricity reduction in Ghana. Sustainable Cities and Society, 59, 102235.

Druckman, A., \& Jackson, T. (2016). Understanding households as drivers of carbon emissions. Taking Stock of Industrial Ecology, 181-203.

Energy Commission. (2018). National Energy Balance 2018. Suruhanjaya Tenaga(Energy Commission). 


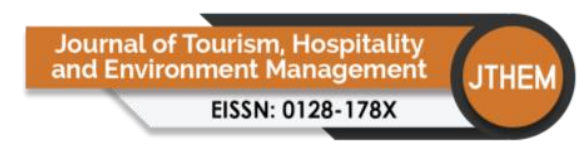

Volume 6 Issue 26 (December 2021) PP. 215-222

DOI 10/35631/JTHEM.626019

Enshassi, A., Elzebdeh, S., \& Mohamed, S. (2017). Drivers affecting household residents' water and related energy consumption in residential buildings. International Journal of Building Pathology and Adaptation, 35(2), 159-175.

Eriksson, L., \& Kjeang, A. (2020). Local organization for promoting energy efficiencyreform of local energy advice service in Sweden. Energy Efficiency, 14(1).

Fijnheer, J. D., Van Oostendorp, H., \& Veltkamp, R. (2019). Household energy conservation intervention: A game versus dashboard comparison. International Journal of Serious Games, 6(3), 23-36.

Gołębiowska, B. (2020). Energy literacy in poland. General Environmental and Social Problems, 2(2), 121-143.

Hobman, E., Stenner, K., \& Frederiks, E. (2017). Exploring everyday energy usage practices in Australian households: A qualitative analysis. Energies, 10(9), 1332.

Imbulana Arachchi, J., \& Managi, S. (2021). Preferences for energy sustainability: Different effects of gender on knowledge and importance. Renewable and Sustainable Energy Reviews, 141, 110767.

Jakučionytė-Skodienè, M., Dagiliūtè, R., \& Liobikienė, G. (2020). Do general proenvironmental behaviour, attitude, and knowledge contribute to energy savings and climate change mitigation in the residential sector? Energy, 193, 116784.

Jareemit, D., \& Limmeechokchai, B. (2019). Impact of homeowner's behaviours on residential energy consumption in Bangkok, Thailand. Journal of Building Engineering, 21, 328335.

Jijie, D., Maxim, A., Roman, T., \& Roșcovan, M. (2021). Public acceptance and support of renewable energy in the north-east development region of Romania. Energies, 14(18), 5834.

Khani, S. M., Haghighat, F., Panchabikesan, K., \& Ashouri, M. (2021). Extracting energyrelated knowledge from mining occupants' behavioral data in residential buildings. Journal of Building Engineering, 39, 102319.

Kowalska-Pyzalska, A., \& Byrka, K. (2019). Determinants of the willingness to energy monitoring by residential consumers: A case study in the city of Wroclaw in Poland. Energies, 12(5), 907.

Kusumadewi, T. V., \& Limmeechokchai, B. (2017). CO 2 mitigation in residential sector in Indonesia and Thailand: Potential of renewable energy and energy efficiency. Energy Procedia, 138, 955-960.

Li, L., Liu, Y., Fan, J., \& Shen, B. (2019). Does the knowledge and acceptance of an increasing block tariffs policy strengthen residents' gas-saving intention? Evidence from household-level survey data. Journal of Cleaner Production, 223, 289-300.

Nie, H., Vasseur, V., Fan, Y., \& Xu, J. (2019). Exploring reasons behind careful-use, energysaving behaviours in residential sector based on the theory of planned behaviour: Evidence from Changchun, China. Journal of Cleaner Production, 230, 29-37.

Pothitou, M., Hanna, R. F., \& Chalvatzis, K. J. (2016). Environmental knowledge, proenvironmental behaviour and energy savings in households: An empirical study. Applied Energy, 184, 1217-1229.

Pothitou, M., Varga, L., Kolios, A. J., \& Gu, S. (2015). Linking energy behaviour, attitude and habits with environmental predisposition and knowledge. International Journal of Sustainable Energy, 36(4), 398-414.

Seebauer, S., \& Wolf, A. (2016). Disentangling household and individual actors in explaining private electricity consumption. Energy Efficiency, 10(1), 1-20. 
Song, Y., Guo, S., \& Zhang, M. (2019). Assessing customers' perceived value of the anti-haze cosmetics under haze pollution. Science of The Total Environment, 685, 753-762.

Song, Y., Zhao, C., \& Zhang, M. (2019). Does haze pollution promote the consumption of energy-saving appliances in China? An empirical study based on norm activation model. Resources, Conservation and Recycling, 145, 220-229.

Stikvoort, B., Juslin, P., \& Bartusch, C. (2017). Good things come in small packages: Is there a common set of motivators for energy behaviour? Energy Efficiency, 11(7), 15991615.

Stojanovski, O., Leslie, G. W., Wolak, F. A., Huerta Wong, J. E., \& Thurber, M. C. (2020). Increasing the energy cognizance of electricity consumers in Mexico: Results from a field experiment. Journal of Environmental Economics and Management, 102, 102323.

Tabatabaei, S. A., \& Klein, M. (2018). The role of knowledge about user behaviour in demand response management of domestic hot water usage. Energy Efficiency, 11(7), 17971809.

Tanaka, K., Sekito, M., Managi, S., Kaneko, S., \& Rai, V. (2017). Decision-making governance for purchases of solar photovoltaic systems in Japan. Energy Policy, 111, $75-84$.

Thøgersen, J. (2018). Frugal or green? Basic drivers of energy saving in European households. Journal of Cleaner Production, 197, 1521-1530.

Trotta, G. (2018). Factors affecting energy-saving behaviours and energy efficiency investments in British households. Energy Policy, 114, 529-539.

Trotta, G. (2020). Electricity awareness and consumer demand for information. International Journal of Consumer Studies, 45(1), 65-79.

Ucal, M. (2017). Energy-saving behavior of Turkish women: A consumer survey on the use of home appliances. Energy \& Environment, 28(7), 775-807.

Zhang, B., Lai, K., Wang, B., \& Wang, Z. (2019). From intention to action: How do personal attitudes, facilities accessibility, and government stimulus matter for household waste sorting? Journal of Environmental Management, 233, 447-458.

Zhang, J., \& Zhang, Y. (2018). Carbon tax, tourism CO 2 emissions and economic welfare. Annals of Tourism Research, 69, 18-30.

Zhang, J., \& Zhang, Y. (2018). Exploring the impacts of carbon tax on tourism-related energy consumption in China. Sustainable Development, 27(3), 296-303. 